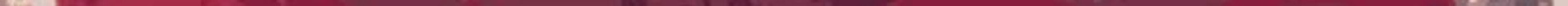




\section{Educación y tecnología}

L as reflexiones y propuestas prácticas asociadas a la educación y la tecnología, así como su entramado complejo de interacciones y expresiones son en la actualidad tareas y compromisos insoslayables; ellas se presentan en un tiempo-espacio histórico en el cual la cultura se transforma por efecto tanto de los eventos educativos como por los fenómenos tecnológicos. De esta manera, la educación y la tecnología se comprenden en sus significados y relaciones como factores esenciales de cambio de la cultura y, por ende, de los sujetos. En esa medida, la cultura es entendida como un entramado de significados construido por las personas en el marco de la vida humana, individual y colectiva, que se expresa en conocimientos, costumbres, valores y actuaciones con un alto contenido simbólico que comparten los sujetos integrantes de un grupo o sociedad.

La revista Pedagogía y Saberes convocó a la comunidad académica a compartir sus reflexiones sobre la relación educación y tecnología con el propósito de reconocer miradas y posturas inéditas, complementarias y diversas, que abran la discusión y permitan fortalecer el pensamiento, el conocimiento y el desarrollo de capacidades para y producir propuestas que ayuden a comprender dicha relación. El dossier contenido sobre esta temática presenta siete artículos. En "Políticas públicas de Tic en Colombia: entre la inclusión digital y formas de resistencia-transformación social" Rocío Rueda y Manuel Franco presentan una revisión crítica sobre la evolución y concepción de la tecnología en el país, principalmente la digital, a partir de las políticas públicas. Concluye que las políticas de Estado en Colombia se basan en un discurso definido como salvacionista, neutral y benevolente. Los autores contrastan esta realidad con el análisis de experiencias de grupos y colectivos que representan empoderamiento y apropiación de las tecnologías.

En "Presencia docente y construcción de conocimiento en una asignatura universitaria modalidad b-learning" Nadia Obando, Andrés Palechor y Diana Arana exponen los resultados de una investigación que concluye que la presencia docente se fortalece en proporción directa a la participación de estudiantes y profesores en las actividades y espacios propios del ambiente virtual investigado. Por otra parte, Antonio Quintana, John Jairo Páez y Patricia Téllez en "Actividades tecnológicas escolares: un recurso didáctico para promover una cultura de las energías renovables" presentan las principales conclusiones de una investigación en la que se evaluó una estructura de actividades tecnológicas escolares orientada al estudio de la tecnología, para lo cual se consideraron aspectos técnicos, sociales y culturales. Como conclusión se afirma la validez de esta estructura y su pertinencia en el entorno escolar.

Faustino Peña y Nelson Otálora en "Educación y tecnología: problemas y relaciones" presentan una reflexión sobre estas dos prácticas entendidas, en su especificidad e interrelación, como fenómenos centrales para el desarrollo de las personas. En ese sentido, postulan algunas ideas relativas a los significados de la educación y la tecnología y estructuran la discusión a través de problemas y preguntas que, enunciados como asuntos críticos, permiten reconocer diferentes posturas y propuestas alrededor de cada práctica y de su relación para, finalmente presentar señalar que las relaciones entre educación y tecnología se sustentan en un conjunto de articulaciones, implicaciones, integraciones y síntesis.

En "Los espacios digitales en permanente definición y construcción. Un análisis desde los elementos formativos" Ana María Vásquez, Laura Sánchez y Wilson Bolívar proponen una reflexión sobre lo que denominan los elementos formativos en el contexto de espacios digitales que les permite concluir que tales espacios se encuentran vinculados con la emergencia de aspectos fundamentales de la subjetividad: la realización personal, la acción, la expresión del ser y la participación, entre otros. En otro sentido, se encuentra la reflexión titulada "Perfil de egreso y empleo en el contexto del avance tecnológico", en ella César Silva analiza el panorama laboral de los egresados de un programa con un currículo basado en competencias, en relación con los puestos de trabajo y la remuneración. La conclusión más relevante es que la formación por competencias no asegura los puestos de trabajo ni tampoco buenas remuneraciones, lo que genera desmotivación en los egresados y, a su vez, despreocupación por la solución y el abordaje de problemáticas sociales.

El último artículo que compone este dossier es un estudio en el que se presenta una "Revisión de la educación y la tecnología desde una mirada pedagógica", en él, Sandra Acevedo realiza un rastreo documental y un análisis categorial de artículos publicados sobre 
el tema entre 1990 y 2017 en la revista Pedagogía y Saberes. Como resultado, presenta tres líneas o nodos alrededor de los cuales se articulan las principales discusiones que circularon en esta publicación seriada en las últimas tres décadas: la crítica que la pedagogía hace al efecto que tienen los medios en la educación, la idea de inclusión a través del uso de la tecnología y la educación virtual, y, finalmente la relación entre subjetividad y experiencia vehiculada por la interacción con entornos virtuales.

En general, se percibe diversidad en los objetos y las perspectivas metodológicas que orientan las reflexiones y las propuestas de los artículos que permiten reconocer por lo menos tres aspectos que articulan los debates. Por una parte, se identifica una fuerte tendencia a entender la educación como escenario para el desarrollo y la formación de las personas a través y en la relación con la tecnología. Así, aparece la educación se enuncia como el escenario para el desarrollo de capacidades y competencias que ponen en juego y despliegan potencialidades humanas. Por otra parte, se reconoce un creciente interés por el debate sobre la subjetividad y, en particular, sobre como ella es el resultado o está determinada por la relación educación y tecnología, lo que obliga a pensar que dicha relación se configura como un campo emergente de conocimiento. Por último, se percibe cierta centralidad alcanzada por el tema de las TIC, principalmente focalizado en asuntos que se refieren a lo digital y lo virtual.

Esperamos que el contenido de este número convoque a la comunidad académica para continuar con la reflexión y el debate de una relación que propone retos formativos para padres y maestros.

Faustino Peña Rodríguez

Universidad Pedagógica Nacional

Nelson Otálora Porras

Universidad Pedagógica Nacional

Coordinadores académicos 